\title{
Reproductive Healthcare Needs and Desires in a Cohort of HIV-Positive Women
}

\author{
Martina L. Badell, Eva Lathrop, Lisa B. Haddad, Peggy Goedken, \\ Minh Ly. Nguyen, and Carrie A. Cwiak \\ Department of Gynecology and Obstetrics, Emory University, 69 Jesse Hill Jr. Dr. SE, Atlanta, GA 30306, USA \\ Correspondence should be addressed to Martina L. Badell, mbadell@emory.edu
}

Received 20 January 2012; Accepted 20 April 2012

Academic Editor: Deborah Cohan

Copyright (C) 2012 Martina L. Badell et al. This is an open access article distributed under the Creative Commons Attribution License, which permits unrestricted use, distribution, and reproduction in any medium, provided the original work is properly cited.

\begin{abstract}
Background. The aim of this study was to determine current contraceptive use, contraceptive desires and knowledge, future fertility desires, and sterilization regret in a cohort of HIV-positive women. Study Design. 127 HIV-positive women receiving care at an urban infectious disease clinic completed a survey addressing their contraceptive and reproductive histories as well as their future contraceptive and fertility desires. Results. The most common forms of contraception used were sterilization (44.4\%) and condoms (41.3\%). Less than 1\% used a long-term reversible method of contraception (LARC) despite these being the methods that best fit their desired attributes of a contraceptive method. Overall, $29.4 \%$ desired future fertility. Only 50.6\% of those sexually active had spoken with a provider within the last year regarding their contraceptive plans. There was a high degree of sterilization regret $(36.4 \%)$, and $18.2 \%$ of sterilized women desired future fertility. Multivariate analysis found women in a monogamous relationship had a statistically increased rate of regret compared to women who were not sexually active (OR 13.8, 95\% CI 1.6-119, $P=0.17$ ). Conclusion. Given the diversity in contraceptive and fertility desires, coupled with a higher rate of sterilization regret than is seen in the general population, integration of comprehensive family planning services into HIV care via increased contraceptive education and access is imperative.
\end{abstract}

\section{Introduction}

Since the mean desired fertility rate in the United States is 2 [1], American women spend most of their reproductive lives attempting to space or prevent pregnancies; however, nearly half of all pregnancies in the USA are unintended (unwanted or mistimed) [2]. Women at highest risk for unintended pregnancies are also at highest risk for HIV and sexually transmitted infection acquisition, including women of minority race, lower education level, and lower socioeconomic status [3]. Approximately 100,000 women of reproductive age in the USA are infected with HIV, and women of color disproportionately account for $80 \%$ of HIVinfected women [4].

The prognosis for people living with HIV has greatly improved and therefore the healthcare community is able to focus on quality-of-life issues rather than only length of life issues [5]. For example, the availability and use of highly active antiretroviral therapy (HAART) has dramatically reduced mother-to-child transmission and allowed HIVpositive women to live longer, healthier lives which in turn has affected their fertility desires $[6,7]$. Cohort studies of HIV-positive women have noted a high use of sterilization and a low use of hormonal contraception, despite desire for future fertility $[8,9]$. Reasons for low use of hormonal or other effective contraception were not explored.

Given their HIV status, often coupled with a lower socioeconomic status, these women represent a vulnerable cohort in need of objective support in regards to their reproductive choices. It remains unclear how advances in HIV therapy have influenced HIV-positive women's reproductive needs and choices. Our study was designed to assess the contraceptive needs and fertility desires of an HIV-positive population of women in order to help direct evidence-based, effective, integrated family planning services into the current HIV care setting. 


\section{Material and Methods}

From December 2008 through January 2010, we recruited a convenience sample of HIV-positive women presenting to outpatient medical care at the Infectious Disease Clinic associated with the Grady Health System in Atlanta, GA, USA. This clinic provides care to a predominately urban and underinsured population of HIV-positive men and women. Inclusion criteria included females 18-50 years old, HIVpositive, nonpregnant, and able to speak, read, understand, and consent in English. Exclusion criteria included women with uncontrolled psychiatric illness, unknown HIV status, pregnancy, history of hysterectomy, or who were unable or unwilling to consent to the study. The Institutional Review Board at the Emory University and the Grady Research Committee approved this study protocol, and all subjects provided verbal informed consent.

Participants completed a self-administered, 35-question written survey. To assure confidentiality, surveys were completed in a private room beside the waiting area. The survey inquired about the subject's demographic characteristics, obstetrical history, HIV medical history, most recent contraception usage, desired contraceptive attributes, knowledge of safety and availability of various contraceptives to HIVpositive women, desire for future fertility, sterilization rates and regret, and whether they have discussed their reproductive choices/desires with their physician. Many of the survey questions had been previously validated in other reproductive healthcare surveys. Prior to study initiation, the survey was piloted with 30 participants in the clinic to assess the understandability and feasibility of administering the survey instrument in this population.

2.1. Statistical Analysis. All statistical analyses were completed using SPSS version 17.0. Tests with $P$ values $<0.05$ were considered statistically significant. Outcomes of interest included contraceptive use, desired contraceptive attributes, contraceptive knowledge, future fertility desires, and sterilization regret. Descriptive statistics were generated. Continuous variables were compared using Student's $t$-test while categorical variables were compared using Chi-square test. Logistic regression was used to generate odds ratios and $95 \%$ confidence intervals for multivariate analyses to identify factors that were associated with sterilization regret and future fertility desire.

\section{Results}

A total of 127 women were surveyed. The subjects had a mean age of 37.8 years (standard deviation 8.4 ) with a range $18-50$ years. The vast majority of subjects self-reported as black (95\%). Subjects' educational background was diverse. The majority of subjects (67.7\%) were unemployed. Most had been pregnant in the past $(91.3 \%)$ and had borne children $(81.6 \%)$, and $37.3 \%$ of subjects had 4 or more prior pregnancies. Nearly half $(47.2 \%)$ were in a monogamous relationship, and $27.6 \%$ were not currently in a sexual relationship. The majority $(60.6 \%)$ reported always using condoms when they had sex. Nearly half $(49.6 \%)$ of the
TABLE 1: Demographics.

\begin{tabular}{|c|c|c|}
\hline & Number & Valid \% \\
\hline \multicolumn{3}{|l|}{ Age } \\
\hline $18-25$ & 13 & $10.2 \%$ \\
\hline $26-35$ & 32 & $25.2 \%$ \\
\hline $36-45$ & 58 & $45.7 \%$ \\
\hline $46-50$ & 24 & $18.9 \%$ \\
\hline \multicolumn{3}{|l|}{ Ethnicity } \\
\hline Black & 120 & $94.5 \%$ \\
\hline Hispanic & 1 & $0.8 \%$ \\
\hline White & 4 & $3.1 \%$ \\
\hline Other & 1 & $3.1 \%$ \\
\hline Missing & 1 & \\
\hline \multicolumn{3}{|l|}{ Education } \\
\hline Did not complete high school & 48 & $37.8 \%$ \\
\hline Completed high school/GED & 39 & $30.7 \%$ \\
\hline At least some college of technical school & 32 & $25.2 \%$ \\
\hline Completed college or above & 8 & $6.3 \%$ \\
\hline Missing & 1 & \\
\hline \multicolumn{3}{|l|}{ Reproductive history } \\
\hline Gravida 1 or more & 115 & $91.3 \%$ \\
\hline Para 1 or more & 102 & $81.6 \%$ \\
\hline Missing & 2 & \\
\hline \multicolumn{3}{|l|}{ Sexual relationship } \\
\hline Monogamous & 60 & $47.2 \%$ \\
\hline Non-monogamous & 10 & $7.9 \%$ \\
\hline Not currently sexually active & 35 & $27.6 \%$ \\
\hline Not sure & 17 & $13.4 \%$ \\
\hline Missing & 5 & \\
\hline \multicolumn{3}{|l|}{ HIV history } \\
\hline Diagnosed $<5$ years ago & 34 & $28.8 \%$ \\
\hline Diagnosed 5-10 years ago & 27 & $21.3 \%$ \\
\hline Diagnosed $>10$ years ago & 63 & $49.6 \%$ \\
\hline AIDS diagnosis & 52 & $40.9 \%$ \\
\hline Currently taking HAART & 96 & $75.6 \%$ \\
\hline
\end{tabular}

women surveyed had been diagnosed with HIV for greater than 10 years, and $28.8 \%$ reported being diagnosed less than 5 years. Overall, $40.9 \%$ had been diagnosed with AIDS and $75.6 \%$ were currently taking antiretroviral medications as prescribed (Table 1).

3.1. Contraceptive Use and Desires. When asked to state the last contraceptive method used, most women reported using female sterilization (44.4\%) or condoms $(41.3 \%)$, with only $24.4 \%$ using any type of hormonal method, and less than $1 \%$ using long-term reversible contraception (LARC) defined as an IUD or implant (Table 2). While less than $60 \%$ of women knew about each of the LARC methods, the most common methods subjects stated they wished to learn more about were the LARC methods and the Nuvaring. Most (91.3\%) thought condoms were safe for HIV-positive women; however, less than half of the participants thought 
TABLE 2: Last contraceptive method used.

\begin{tabular}{lcc}
\hline Method & Number* $^{*}$ & Percentage \\
\hline Sterilization & 56 & $44.4 \%$ \\
Condoms & 52 & $41.3 \%$ \\
Depo-Provera & 20 & $15.9 \%$ \\
Abstinence & 8 & $6.3 \%$ \\
None & 8 & $6.3 \%$ \\
Pill & 7 & $5.6 \%$ \\
Patch & 3 & $2.4 \%$ \\
Withdrawal & 2 & $1.6 \%$ \\
\hline${ }^{n}=126,1$ missing. & & \\
Overall, 0.8\% each used IUD, diaphragm, or cervical cap, NuvaRing, and \\
natural family planning.
\end{tabular}

TABle 3: Contraceptive methods HIV-positive subjects have heard of/think are safe to use.

\begin{tabular}{lcc}
\hline Method & $\begin{array}{c}\text { Have heard of number } \\
(\%)\end{array}$ & $\begin{array}{c}\text { Think are safe number } \\
(\%)\end{array}$ \\
\hline Condoms & $115(92.7 \%)$ & $115(91.3 \%)$ \\
Pill & $114(91.6 \%)$ & $55(43.7 \%)$ \\
Sterilization & $112(90.3 \%)$ & $41(32.5 \%)$ \\
Depo-Provera & $112(90.3 \%)$ & $46(36.5 \%)$ \\
Patch & $93(75.0 \%)$ & $30(23.8 \%)$ \\
Abstinence & $77(62.1 \%)$ & $78(61.9 \%)$ \\
Implant & $72(58.1 \%)$ & $23(18.3 \%)$ \\
IUD & $68(54.8 \%)$ & $26(20.6 \%)$ \\
Diaphragm & $65(52.4 \%)$ & $28(22.2 \%)$ \\
Withdrawal & $61(49.2 \%)$ & $28(22.2 \%)$ \\
Plan B & $54(43.5 \%)$ & $22(17.5 \%)$ \\
Nuvaring & $51(41.4 \%)$ & $23(18.3 \%)$ \\
Missing & 3 & 1 \\
\hline
\end{tabular}

the pill, Depo-Provera, the patch, the IUD, the Nuvaring, or implant were safe (Table 3).

Subjects were asked how satisfied they were with their current contraceptive method: $58.1 \%$ were very satisfied, $17.9 \%$ were somewhat satisfied, and $23.9 \%$ were somewhat or not at all satisfied. When asked to choose the three most important factors to them when choosing a birth control method, the most frequently cited attribute was ease of use, followed by efficacy at preventing pregnancy, and low risk of side effects (Table 4). Subgroup analyses of contraceptive use and desires in women $\leq 45$ years of age were not significantly different with the exception that knowledge of sterilization was lower $(76.0 \%$ versus $90.3 \%, P=0.005)$.

3.2. Desire for Fertility and Discussion with Providers. Overall, $29.4 \%$ of those surveyed desired future fertility. Of these almost half $(46.0 \%)$ were unsure of when they desired to become pregnant in the future, and only $8.1 \%$ desired to become pregnant within the next year. The factor most strongly correlated with future fertility desire was age. Univariate analysis found that women with greater than 4 prior live births were significantly less likely to desire
TABLE 4: Most important attributes of contraceptive method (women were asked to pick their top 3 attributes).

\begin{tabular}{lcc}
\hline Attribute & Number* & Percentage \\
\hline Easy to use & 80 & $64.5 \%$ \\
Works well at preventing pregnancy & 50 & $40.3 \%$ \\
Low in side effects & 44 & $35.5 \%$ \\
Low in cost & 41 & $33.1 \%$ \\
Decreases menstrual cycles & 31 & $24.8 \%$ \\
Works on the long term & 25 & $20.2 \%$ \\
Maintains regular menstrual cycles & 24 & $19.4 \%$ \\
Decreases period symptoms & 22 & $17.7 \%$ \\
Quickly reversible & 10 & $8.1 \%$ \\
Hormone-free & 8 & $6.5 \%$ \\
No action required during sex & 4 & $3.2 \%$ \\
\hline${ }_{n}=124,3$ missing. & &
\end{tabular}

future pregnancy; however, when controlling for age, this association was no longer significant. In a multivariate model looking at predictors of future fertility desire, age was found to be significantly associated (OR 1.17, 95\% CI $1.08-1.26, P<0.001)$ with younger age associated with increased fertility desire. In addition, women not currently in a relationship were significantly less likely to desire future fertility compared to women in a monogamous relationship (OR $0.26,95 \%$ CI $0.09-0.77, P=0.015$ ). In multivariate analyses, education, reproductive history, HIV history, having a diagnosis of AIDS, or using HAART was not associated with future fertility desire. Only $50.6 \%$ of those sexually active had spoken with a provider in the past year regarding their contraceptive plans. Approximately onethird $(32.1 \%)$ reported that they had either never spoken to a provider or it was greater than 5 years ago.

3.3. Female Sterilization. The mean age of sterilization was 28 years of age with a range 21-39 years. More than half (56.4\%) reported that HIV/AIDS was one of the reasons they chose to be sterilized. Sterilization regret was reported in $36.4 \%$, and $18.2 \%$ of these women desired to become pregnant in the future. Multivariate analysis looking at age, education, reproductive history, sexual relationship, HIV history, AIDS diagnosis, and use of HAART medication found that women in a monogamous relationship had a statistically increased rate of regret compared to women who were not sexually active (OR 13.8, 95\% CI 1.6-119, $P=$ 0.017). Age at sterilization and reporting that HIV/AIDS was a factor in deciding to become sterilized were not significantly associated with regret.

\section{Discussion}

Our sample represented an older reproductive-aged, predominantly black and parous, urban, underinsured cohort, with a high percentage functioning with a long-term diagnosis of HIV. Female sterilization was the most commonly used form of contraception in our subjects (44.4\%). Massad et al. reported $23 \%$ use of sterilization, $30 \%$ use of barrier 
methods, and less than $10 \%$ use of hormonal methods among US HIV-positive women in a 2007 study [8]. The increased rate of sterilization we found may be related to the characteristics of our cohort as it is similar to the 46.4 rate reported in age-comparable samples of the general US population [10]. Although a substantial number of these HIV-positive women had undergone sterilization, their contraceptive and fertility desires suggest that effective, reversible contraceptive methods are more suitable.

Only $22.9 \%$ of subjects were using any type of hormonal method, and less than $1 \%$ used long-term reversible contraception (LARC). Again, this is similar to age-comparable rates of method use reported in the general population [10]. This may be in part due to the fact that less than half of the subjects thought the pill or Depo-Provera was safe for HIV-positive women to use and less than a quarter thought the LARC methods were safe. Concern in the literature exists regarding hormonal contraceptive use in women with HIV. Several studies of hormonal contraceptive use in HIV-positive women have indicated an association with increased shedding of HIV-1 DNA in the genital tract, HIV acquisition and transmission, or clinical disease progression [11-14]. However, multiple other studies have failed to demonstrate a link between contraceptive use and HIV-1 acquisition, transmission, and progression [1518]. The World Health Organization (WHO) in February 2012 concluded, upon the strength of the epidemiological evidence and analysis of risks and benefits to country programmes, that no restrictions (MEC category 1) be placed on the use of any hormonal contraceptive method for women living with HIV [19]. In addition, based on systematic reviews of all available literature, the Centers for Disease Control USA Medical Eligibility Criteria (MEC) for Contraceptive Use classifies all hormonal and LARC methods as acceptable for use (category 1 or 2) in HIVpositive women. Information regarding medical eligibility for all contraceptive methods in women with HIV/AIDS is available at http://www.cdc.gov/reproductivehealth/usmec.

Although small studies have noted decreased hormonal levels in the plasma of women using certain classes of antiretrovirals, there is no evidence that this leads to an increase in contraceptive failure in this population. The USA Department of Health and Human Services recommends additional or alternative (nonoral hormonal) contraception for HIV-infected women taking most nonnucleoside reverse-transcriptase inhibitors or protease inhibitors and recommends avoiding coadministering combined OCs with fosamprenavir [20]. Alternatively, Depo-Provera was found to have no interactions with several antiretroviral agents $[21,22]$. Consistent use of condoms in addition to hormonal contraceptives is strongly recommended to prevent HIV transmission and in addition may compensate for any potential reduction in efficacy or increased viral shedding with hormonal contraceptives. Our results suggest that additional patient counseling is required to educate HIVinfected women regarding their risks as they appeared to underestimate the safety profile of most effective, reversible contraceptive methods.
When asked which attributes the subjects most desired from their contraceptive method, they chose ease of use, effectiveness, and low risk of side effects. Given these factors, it is not surprising that so many subjects chose female sterilization; however, given the substantial rate of sterilization regret, the most suitable methods appeared to be LARC methods. Like sterilization, the LARC methods (progestin-only IUD, copper IUD, and the progestin-only implant) are all rated as having "top tier efficacy" per the World Health Organization because they have a typicaluse failure rate of less than $1 \%$ [23]. Also like sterilization, typical-use failure rates of LARC methods are comparable to their perfect-use failure rates because little action is required by the user. Because LARC provides either the lowest hormonal levels (progestin-only IUD, progestin-only implant) or no hormones, they have low side effect profiles and few contraindications to use. Per The US Medical Eligibility Criteria for Contraceptive Use, even women with AIDS can have implants placed (category 1 ) and may have IUDs placed with close followup or if no other method is available or acceptable (category 2 or 3 ). Perhaps most important to this population, the reversibility of LARC enables the use of highly effective contraception without the risk of sterilization regret. The World Health Organization and the American Congress of Obstetricians and Gynecologist (ACOG) state that intrauterine devices (IUDs) are a safe contraceptive method for HIV-infected women [4].

Of the women in the study who had been sterilized, one-third (36.4\%) regretted their sterilization, and $18.2 \%$ reported they desired children in the future. Stanwood et al. found similar rates of HIV-positive women sterilized (47\%) and wanting children after sterilization (12\%) [9]. However, the United States Collaborative Review of Sterilization found an overall rate of sterilization regret of $7.5 \%$ at 7 years in the general population [24]. It is also interesting that in our sample, an additional $18.2 \%$ stated they regret their tubal sterilization although they do not currently desire future fertility. A prior systematic review evaluating age and risk of sterilization regret found that women under 30 were about twice as likely as those over 30 to express regret [25]. Our findings were not consistent with this; however, we did find that women currently in a monogamous relationship had statistically higher rates of regrets than those not in a relationship. Future relationship status may be a much more difficult factor to foresee preoperatively than one's age as a predictor of future regret. Nevertheless, our results indicate the need for more in-depth preprocedure counseling in an attempt to decrease the rate of regret in this population.

The relatively high rates of tubal ligation and of tubal regret in our population highlight the importance of our need to counsel HIV-positive women on highly effective reversible contraceptive methods, especially as they are greatly underused and yet appear to suit their contraceptive desires. It also highlights the importance of screening them regarding their future fertility desires. ACOG currently recommends that reproductive plans, including preconception counseling and counseling regarding reversible methods of contraception, should be discussed with HIV-infected women of childbearing age [4]. 
Our study has the following limitations. As this survey included sensitive topics, social desirability and stigma may have biased respondents' answers. Our study population received care in an academic, urban setting and therefore may not be generalizable to all HIV-positive women in care. As this was a cross-sectional study, we can only make findings of associations, not definitive conclusions on cause and effect.

\section{Conclusions and Implications}

Women acquiring HIV through heterosexual relationships are currently the largest growing group of HIV-positive patients. Given current therapies, this population is living longer, healthier lives with access to HIV care. Therefore it is important that providers ask HIV-positive women about their reproductive needs and discuss contraception and STI prevention as part of their routine care. Based on our results this population is most commonly using sterilization for contraception despite an unfortunately high level of regret. In addition, this population is under-using LARCs despite these being the type of method they most desire. It is important that providers ask HIV-positive women about their reproductive needs and desires, discuss contraception, and provide preconception counseling if appropriate. There has been little progress integrating family planning services and HIV/AIDS care. Often clinic staff views family planning and HIV prevention as independent services and are not trained to administer them together [26]. Governments and funding agencies have a growing awareness of the need to address the reproductive choices of HIV-positive women and agree that HIV/STI and family planning services should be integrated [27, 28]. Partnerships between HIV/AIDS services and family planning services may be more responsive to the needs of reproductive-age HIV-positive women and may be more likely to provide complete, high-quality care.

\section{References}

[1] S. K. Henshaw, "Unintended pregnancy in the United States," Family Planning Perspectives, vol. 30, no. 1, pp. 24-46, 1998.

[2] L. B. Finer and S. K. Henshaw, "Disparities in rates of unintended pregnancy in the United States, 1994 and 2001," Perspectives on Sexual and Reproductive Health, vol. 38, no. 2, pp. 90-96, 2006.

[3] UNAIDS, "Report on the global AIDS epidemic: a UNAIDS 10th anniversary special edition: executive summary," Joint United Nations Programme on HIV/AID, UNAIDS, Geneva, Switzerland, 2006.

[4] ACOG Committee on Practice Bulletins-Gynecology, "ACOG Practice Bulletin No. 117: gynecologic care for women with human immunodeficiency virus," Obstetrics and gynecology, vol. 116, no. 6, pp. 1492-1509, 2010.

[5] H. Boonstra, "Meeting the sexual and reproductive health needs of people living with HIV," Issues in Brief (Alan Guttmacher Institute), no. 6, pp. 1-4, 2006.

[6] Centers for Disease Control and Prevention, "Epidemiology of HIV/AIDS-United States, 1981-2005," Morbidity and Mortality Weekly Report, vol. 55, no. 21, pp. 589-592, 2006.

[7] E. Z. Aaron and S. M. Criniti, "Preconception health care for
HIV-infected women," Topics in HIV Medicine, vol. 15, no. 4, pp. 137-141, 2007.

[8] L. S. Massad, C. T. Evans, T. E. Wilson et al., "Contraceptive use among U.S. women with HIV," Journal of Women's Health, vol. 16, no. 5, pp. 657-666, 2007.

[9] N. L. Stanwood, S. E. Cohn, J. R. Heiser, and M. Pugliese, "Contraception and fertility plans in a cohort of HIV-positive women in care," Contraception, vol. 75, no. 4, pp. 294-298, 2007.

[10] W. D. Moshe and J. Jones, "Use of contraception in the United States: 1982-2008. National Center for Health Statistics," Vital and Health Statistics, vol. 23, no. 29, 2010.

[11] D. B. A. Clemetson, G. B. Moss, D. M. Willerford et al., "Detection of HIV DNA in cervical and vaginal secretions: prevalence and correlates among women in Nairobi, Kenya," Journal of the American Medical Association, vol. 269, no. 22, pp. 2860-2864, 1993.

[12] A. Kovacs, S. S. Wasserman, D. Burns et al., "Determinants of HIV-1 shedding in the genital tract of women," Lancet, vol. 358, no. 9293, pp. 1593-1601, 2001.

[13] C. C. Wang, R. S. McClelland, J. Overbaugh et al., "The effect of hormonal contraception on genital tract shedding of HIV1," AIDS, vol. 18, no. 2, pp. 205-209, 2004.

[14] R. Heffron, D. Donnell, H. Rees et al., "Hormonal contraceptive use and risk of HIV-1 transmission: a prospective cohort analysis," Lancet Infectious Diseases, vol. 12, pp. 19-26, 2012.

[15] C. S. Morrison, B. A. Richardson, F. Mmiro et al., "Hormonal contraception and the risk of HIV acquisition," AIDS, vol. 21, no. 1, pp. 85-95, 2007.

[16] I. De Vincenzi, R. A. Ancelle-Park, J.-B. Brunet et al., "Comparison of female to male and male to female transmission of HIV in 563 stable couples," British Medical Journal, vol. 304, no. 6830, pp. 809-813, 1992.

[17] E. M. Stringer, M. Giganti, R. J. Carter, W. El-Sadr, E. J. Abrams, and J. S. A. Stringer, "Hormonal contraception and HIV disease progression: a multicountry cohort analysis of the MTCT-Plus Initiative," AIDS, vol. 23, no. 1, supplement 1, pp. S69-S77, 2009.

[18] K. M. Curtis, K. Nanda, and N. Kapp, "Safety of hormonal and intrauterine methods of contraception for women with HIV/AIDS: a systematic review," AIDS, vol. 23, no. 1, pp. S55S67, 2009.

[19] "Hormonal contraception and HIV technical statement," World health organization, 2012, http://whqlibdoc.who.int/ hq/2012/WHO_RHR_12.08_eng.pdf.

[20] "Panel on Antiretroviral Guidelines for Adults and Adolescents," Guidelines for the use of antiretroviral agents in HIV-1infected adults and adolescents. Bethesda (MD): Department of Health and Human Services; 2009, http://www.aidsinfo.nih .gov/ContentFiles/AdultandAdolescentGl.pdf.

[21] K. Nanda, E. Amaral, M. Hays, M. A. M. Viscola, N. Mehta, and L. Bahamondes, "Pharmacokinetic interactions between depot medroxyprogesterone acetate and combination antiretroviral therapy," Fertility and Sterility, vol. 90, no. 4, pp. 965-971, 2008.

[22] D. H. Watts, J. G. Park, S. E. Cohn et al., "Safety and tolerability of depot medroxyprogesterone acetate among HIV-infected women on antiretroviral therapy: ACTG A5093," Contraception, vol. 77, no. 2, pp. 84-90, 2008.

[23] R. A. Hatcher, J. Trussell, A. Nelson, W. Cates, D. Kowal, and M. Policar, Contraceptive Technology, Ardent Media, Atlanta, Ga, USA, 20th edition, 2011.

[24] S. D. Hillis, P. A. Marcheanks, L. R. Tylor, and H. B. Peterson, "Poststerilization regret: findings from the United 
States collaborative review of sterilization," Obstetrics and Gynecology, vol. 93, no. 6, pp. 889-895, 1999.

[25] K. M. Curtis, A. P. Mohllajee, and H. B. Peterson, "Regret following female sterilization at a young age: a systematic review," Contraception, vol. 73, no. 2, pp. 205-210, 2006.

[26] D. Daley, "Reproductive health and AIDS-related services for women: how well are they integrated?" Family Planning Perspectives, vol. 26, no. 6, pp. 264-269, 1994.

[27] W. Cates, Q. Abdool Karim, W. El-Sadr et al., "Global development. Family planning and the millennium development goals," Science, vol. 329, no. 5999, p. 1603, 2010.

[28] W. Cates Jr. and K. M. Stone, "Family planning, sexually transmitted diseases and contraceptive choice: a literature update. Part II," Family Planning Perspectives, vol. 24, no. 3, pp. 122-128, 1992. 


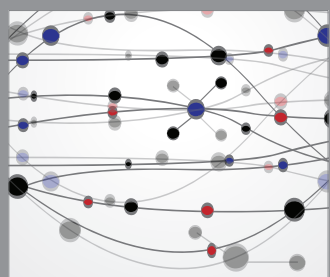

The Scientific World Journal
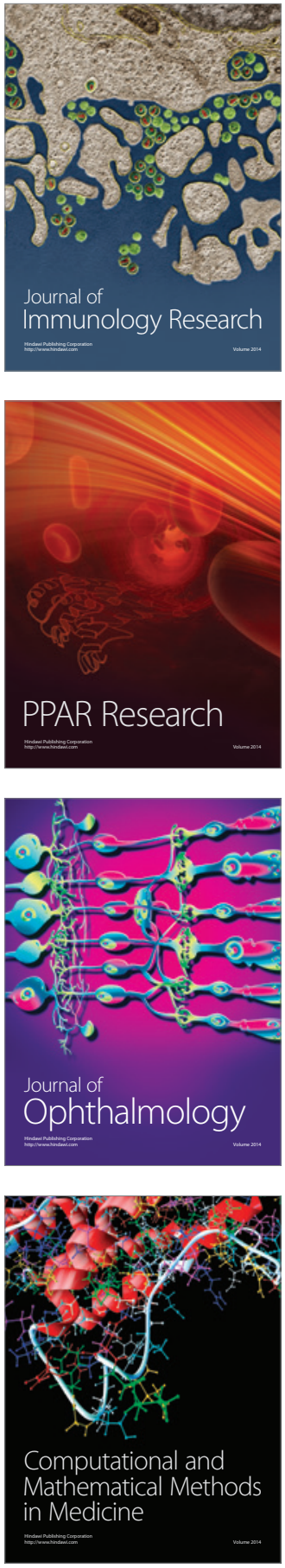

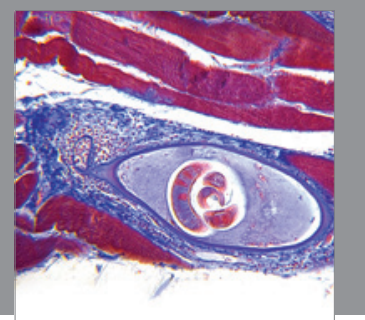

Gastroenterology

Research and Practice
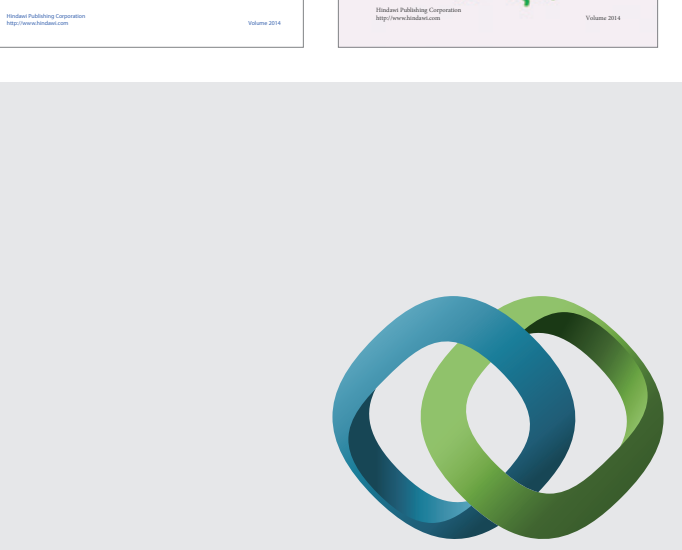

\section{Hindawi}

Submit your manuscripts at

http://www.hindawi.com
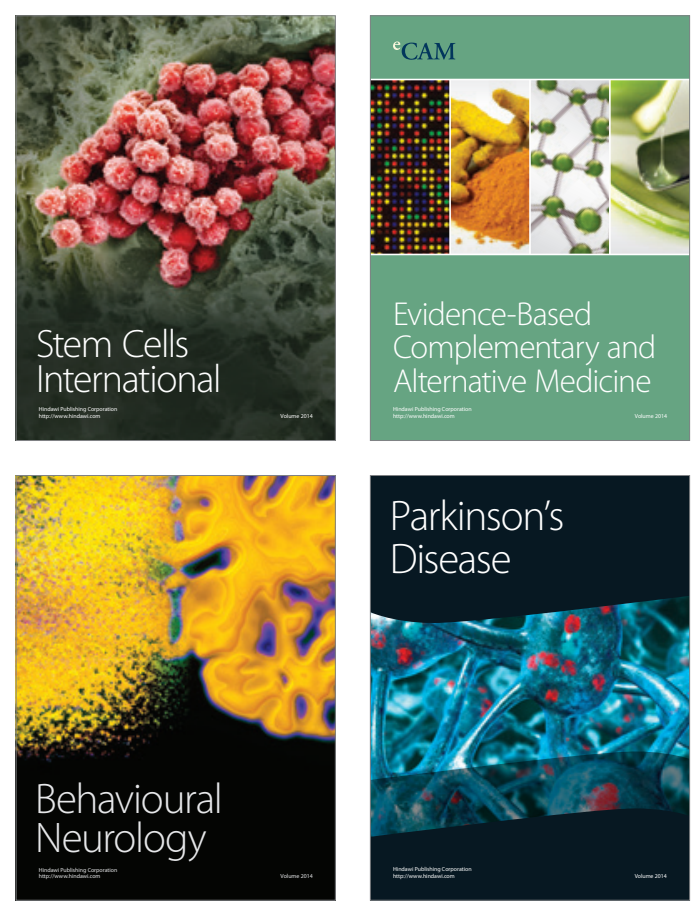

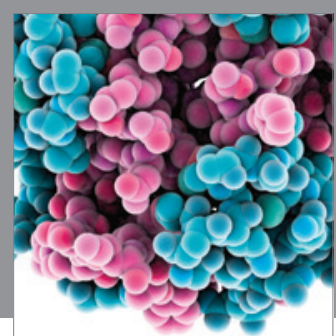

Journal of
Diabetes Research

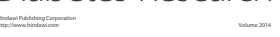

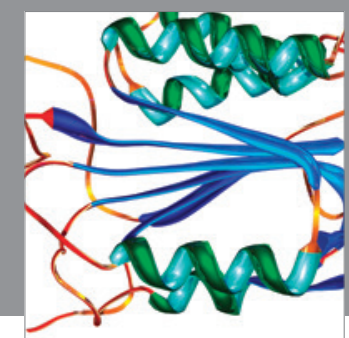

Disease Markers
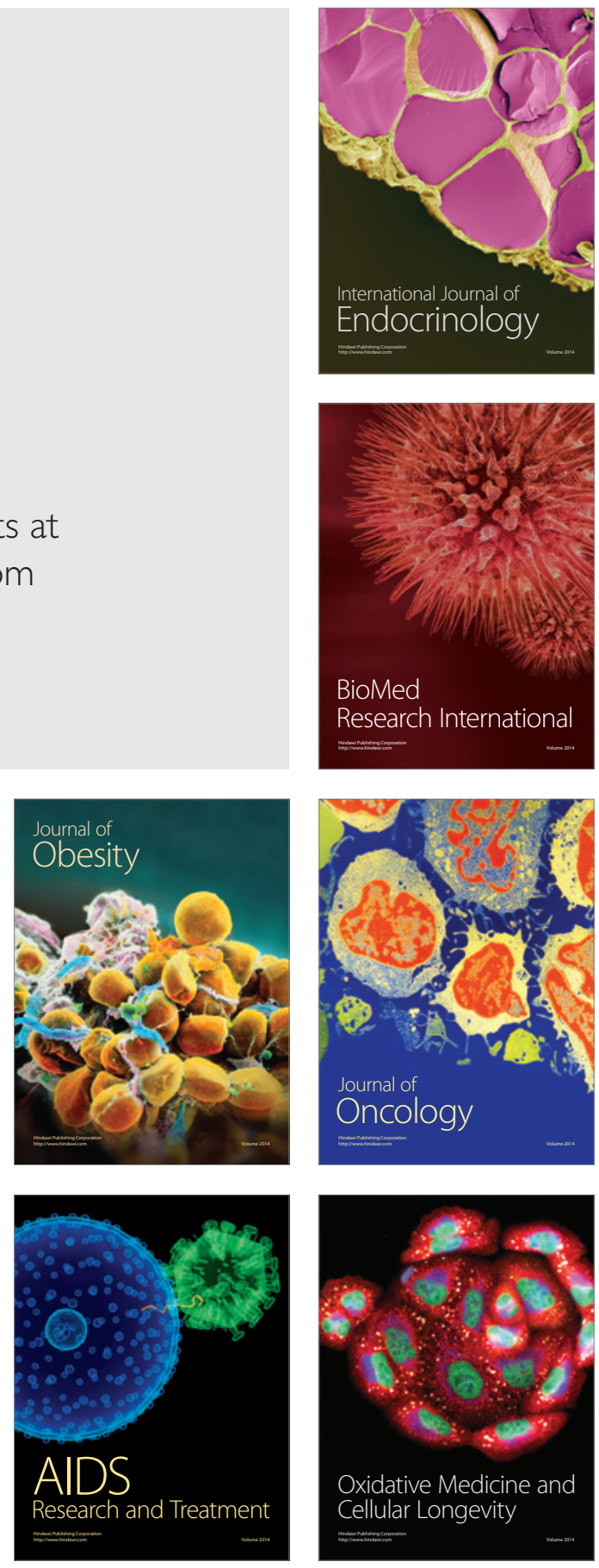